New Approaches to Managing, Marketing, and Money for Maintaining a Core Facility (4M's)

MSA Facility Operation and Management Focused Interest Group workshop (2006)

Organized and facilitated by: Debby Sherman, Purdue University dsherman@purdue.edu

\section{Part la: Case Study: Strategic plan for an EM Facility}

Elaine Humphrey

I took over the facility in 1996 . We had aging equipment, no assistance, there were huge budget cuts that year and I was told, "There was no money. The only money you're gonna get are your wages. Everything else has to come from user fees." I had to find funds for service contracts and we had to increase our user base.

I figured I would have to find an assistant because there is no way one can run a TEM, an SEM and confocal and light microscope facilities alone. So I found a grant called "First Job in Science and Technology" which would give me a graduate student for one year, and we had a summer student who had just graduated and was looking for a job before she went on to graduate school. She learned really fast and by February she was excellent, but by May/June we were back into the same boat again. So we got another "First Job in Science." So three years running we had a "First Job in Science" grant and the faculty decided this wasn't any good. So they went off to see the VP for Research and she gave us $\$ 25,000$, which was enough at least for part of a technical position. Well, once you get a good technical position going, your user base goes up because you can do more work and there's more service work going on, and then you get to need another technical position.

One of the ways that we managed to do this is we got this confocal and decided that the only way we were going to get people to use it was to train them and let them get on with it. So, we ran a one and a half day workshop that turned out to be so successful that pretty soon it was six weeks to get on the microscope. Most users don't want to know a whole lot about the nitty-gritty details of how the microscope works. They want to sit down, get their images and go. A lot of the training is to make sure that they're not going to trash the microscope. They have to be able to leave it for the next person coming in, but that means you have to have technical staff that are going to look after the microscope for you and police it.

Now, the faculty was all too busy to write instrumentation grants, so I had to learn how to write them. In the last 10 years I suppose we've managed about $\$ 5$ million Canadian and $\$ 1.75$ million in the last year.

If you have the service contracts and money for personnel, you can keep the costs down. Keeping the costs down means more researchers come and use your facility, which means you can then put in big user numbers for your next grant. We have built up to over 900 users from about 258 account holders, and last year we had three full time technicians and a half time office person. The main equipment we have besides confocal is two TEMs (one with cryo) and two SEMs ( a Field Emission with cryo and a variable pressure); both of those have telepresencing, A graduate student coming in who is looking at their specimen for the first time can call up their supervisor, no matter where he is in the world, and say "Will you look at this website? Can you see this picture? What am I looking at?" It works out very well.

The microwave processing has also worked really well for us. You can do a three-day processing protocol in two to three hours in the microwave. So for teaching courses, it means you can teach sample preparation in an afternoon without a problem.

When you're looking at doing a budget plan this is what I had:

1) Equipment is the most important thing because without good equipment you're not going to get users. I think acquisition and maintenance of equipment is at the top of the list.

2) Training the users and the staff to look after that equipment is also important.

3) Providing service depends on where you are. Some people are all service only and they don't let anybody near their microscopes. We would never have survived on that regime

4) After hours access is a huge headache, of course.

5) Funding-service, contracts and personnel

6) Space-we never have enough.

7) Where the future is going

Using this information, I wrote a strategic plan that provided the outline for moving forward.

So that was the scenario-writing grants; getting technicians, getting new equipment, being able to look after the equipment, and training. It's all about training your users so they don't break your equipment.

Question: Do you cover all the cost of running the facility with this?

Answer: The only money that came in was my wages. Everything else had to be either grants or user fees. The user fees we charge for inside users are $\$ 25.00 /$ hour for the TEM, $\$ 15 / \mathrm{hr}$ for the variable pressure SEM, and the confocals, and $\$ 11.00 / \mathrm{hr}$ for the light microscopes. We have a three tier system: inside users are departments that put $\$ 4000.00$ a year into the facility, and we have about eight of them. Outside users are non-contributing university departments who get charged two and half times the inside user rate. Commercial users are charged five times the inside user rate.

New Speaker: I just want to make a comment about the "competition thing" because at our university I have competition. I manage a Life Science Microscopy facility. There is also a Material Science Microscopy Facility, and we're essentially competing for the same customers. People on campus will go where they get the best quality, the best equipment, the best deal-that's just the way it goes. I do spend a fair amount of time sizing up my competition and trying to position myself to do things that they cannot do at the present time and probably will never do. My direction is cryo-working with any type of hydrated samples, not just biological. I know the Materials Department does not want cryo or hydrated samples near their microscopes, so we have a natural difference. My facility is funded through the colleges of Science, Agriculture, Vet Medicine and Pharmacy, However, Engineering makes up at least 1/3 of my users because material scientists have a need to see hydrated samples now and then. So we're finding there are more and more opportunities for essentially luring in users from the other side of campus by getting out, marketing our product and making something available that they don't have in their backyard. 
The State of the Art, Revolutionary

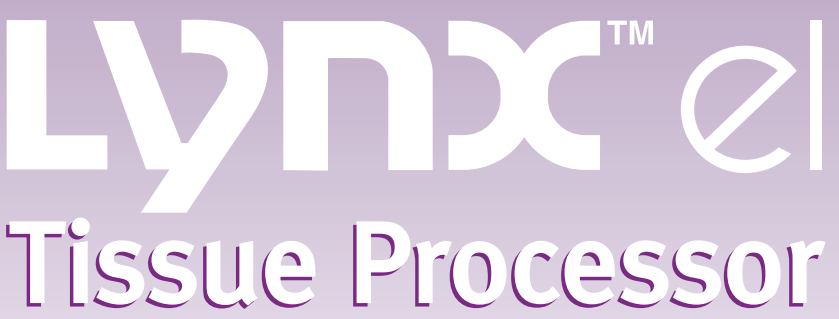

The EMS LMNX Automated Tissue Processor now made even better... for Electron Microscopy and Light Microscopy.

Dramatically reduce your sample preparation cost and time with improved reproducible results!!

The EMS LMNX allows for the processing of tissue all the way through $100 \%$ resin.

\section{Primary uses:}

- Ultrastructural Studies

- Extremely Hard Tissues - Undecalcified Bone

- High Resolution Light Microscopy

- Immunohistochemistry

- Dehydration for SEM

- Deparaffinization

- En-bloc Staining

- And Much More

This state of the art Automated Tissue Processor has many unique features making the unit the most versatile and reliable unit on the market at a very competitive price.

\section{Features:}

- Stainless Steel Working Surfaces

- Enclosed Benchtop Unit

- Reagent Turntable/ Max of 56 Specimens

- 20 Reagent Vials/Cycle

- Temp Range of $4^{\circ} \mathrm{C}-60^{\circ} \mathrm{C}$

- Built in Exhaust Fan

- Alarm Monitoring System

- Multiple Safety Features

- Battery Back Up

- Storage of 10 Programs/ Each with 20 Pre-programmable Steps

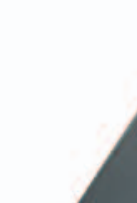

ras
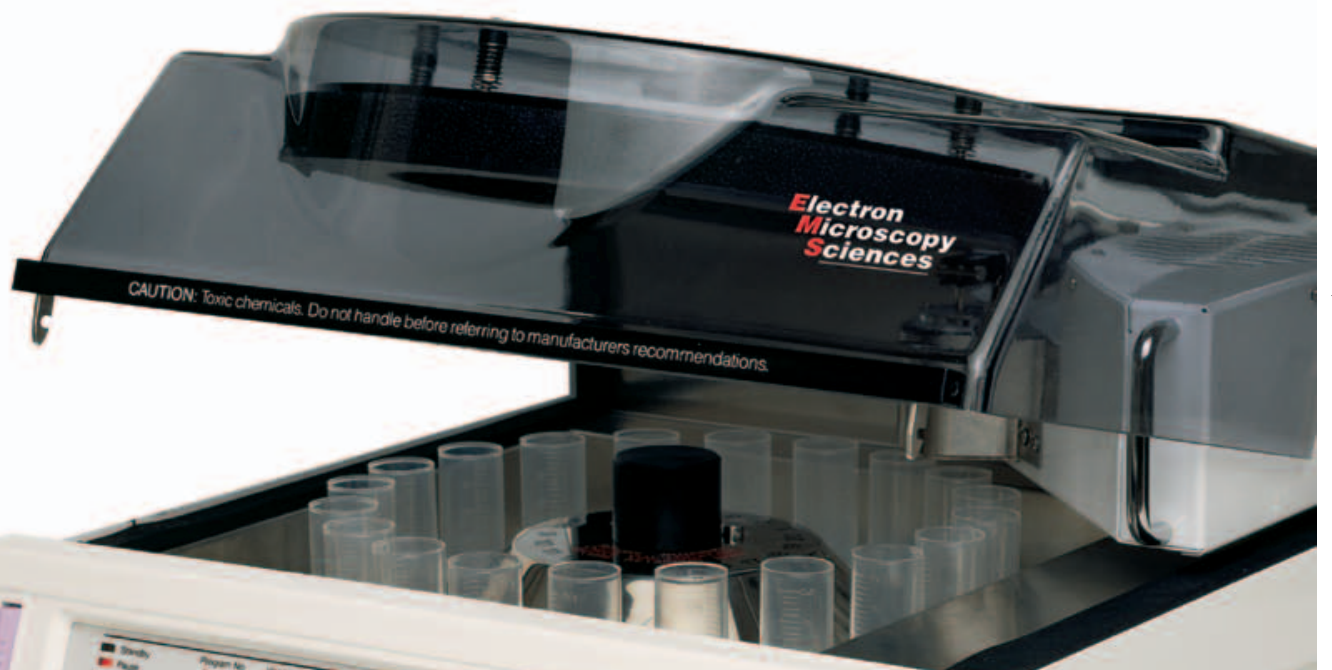

- Printer Output

- Delay Start of Programs

- And Much More...

\begin{abstract}
arket
\end{abstract}

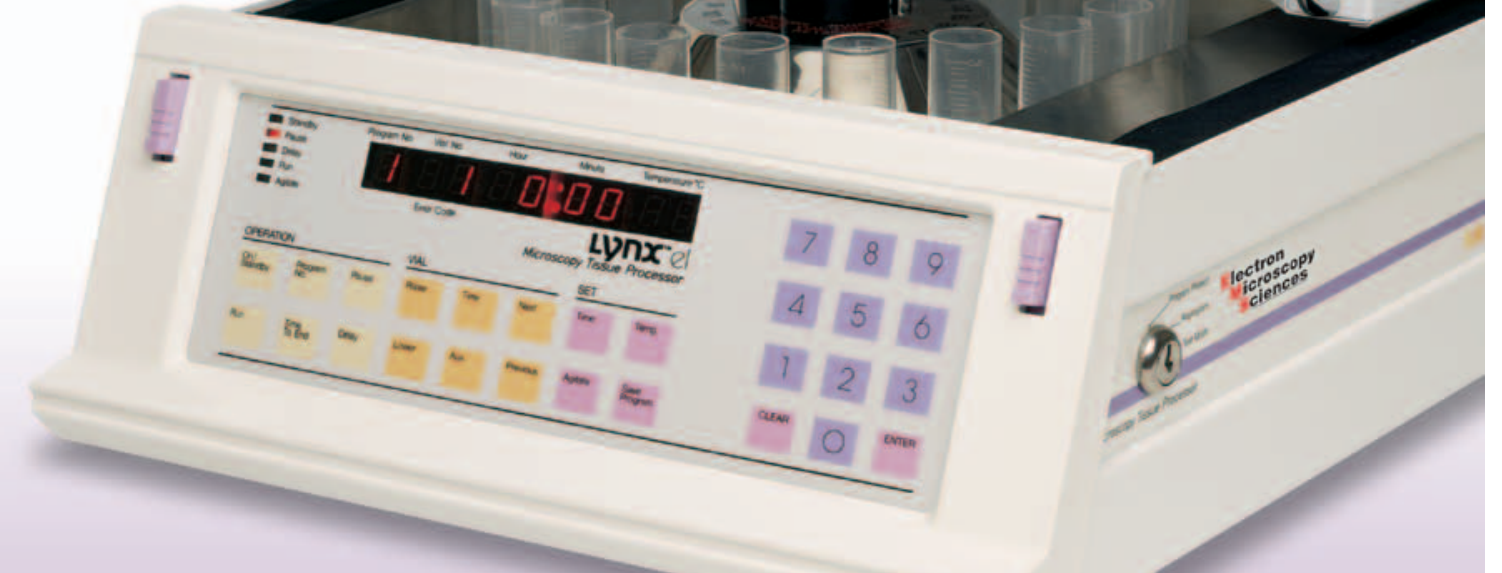

For more information or a complete brochure on the "LnNX" Automated Tissue Processor, please call or write us today.

\section{Electron Microscopy Sciences 1560 Industry Road P.O. Box 550 - Hatfield, PA 19440} tel: 2 I5.4 I2.8400 fax:2 I5.4 I2.8450 email:sgkcck@aol.com web:www.emsdiasum.com 
Elaine Humphrey: I had that kind of competition as well when I first took over, but what we did was to get all the lab managers together for a networking session. So if Mary over in Materials had somebody who wanted to look at bacteria, shed send them over to me. I don't have an EDX on anything except the variable pressure scopes and we don't use it so often. So when people come to me once every two or three years for EDX, I send them over to Mary. She's the one with the expertise in it. We work really well together.

\section{Part Ib: How to Make a Business Plan for Facility Maintenance and Growth.}

\section{Donald A. Blewett \\ Burton D. Morgan Center for Entrepreneurship, Purdue University}

In case you didn't realize it, one of the things that is important about a business plan is to have an enthusiastic champion. I don't know if I've seen a person that has represented what she does more enthusiastically than Elaine did just now.

One of the reasons why I asked Elaine to go first was there's a lot of preparatory work that goes in place before you put together a business plan. Elaine did a very nice job in planning, and one of the key things in her Strategic Plan was that she took planning and made it a part of the business plan. A "S.W.O.T." Analysis is an exercise that you go through when you are dealing with an enterprise that talks about Strengths, Weaknesses, Opportunities and Threats. Elaine put together the S.W.O.T. Analysis in addition to the current facility description and wish lists and that was extremely helpful in putting together her business plan.

You will be writing a business plan for an audience and there are a lot of audiences-associates and colleagues, employees, senior management (no matter who you are or where you are, you all have senior management to deal with), suppliers and vendors (again, if you are working closely with people who are involved in your enterprise, suppliers and vendors would be extremely important), talented people and potential strategic collaborators. They want to know what you're about; they want to know what you're doing, and this is the opportunity for you to tell them. Not to be flip about it, but every once in a while you may lose direction on what you want to do, on what you are trying to accomplish. So your business plan that you're putting together is very likely going to be as much for yourself as it is for anybody else.

1) Executive Summary: First of all, the Executive Summary is generally the first section in a business plan. The Executive Summary is designed to be written last-don't write your Executive Summary first, write it last, primarily because if you wrote it first you would be changing it constantly. Here are some questions that you need to answer:

a. Does your Executive Summary convey to the reader that you have an understanding of what your business is?

b. Does your Executive Summary draw your reader in and say, "Read on so that you understand what we're about"?

c. Does it cover the most important points of your business plan?

d. Does your Executive Summary contain highlights of your enterprise-its products; its markets; the financial position; and its performance both current and objective? In a lot of cases we're going to be talking about a business plan that not only deals with historical fact (Where have you come from?), but what you're planning on, and this is one of the things that Elaine did was to build into her strategic plan a future. e. Does your Executive Summary contain knowledge of your industry, management team and the financial reports along with how you intend to make money and your fee structure? Elaine ticked through very quickly what her fee structure was, but as you heard it was a multi-tiered fee structure and that's especially important to keep in mind when you're trying to load your fee structure in such a way that you want to make money for your enterprise and for your laboratory. You also want to make sure that you aren't pricing yourself out of a market.

2) Vision: This is an interesting part of it and this is sometimes termed the "squishy part of it all." It's the visions, the missions and those kinds of things that again convey to the reader who you are and what you're all about. It should be reality based not grandiose; it should be focused and not too idealistic. The Managing Editor should be the initial author, but that doesn't mean there shouldn't be other collaborators in the development of the Vision Statement. Key members of the management team should have input. You can't lock the door on anybody that's working with the enterprise. It should lay out the path for the laboratory to stretch its possibilities; it should be simple, believable, achievable and understood. This is kind of a flip statement but, it's really kind of true, the best Vision Statement that you can have is to resolve to provide real products and services to real people who are going to buy them with real money.

3) Mission Statement: The Mission Statement, again, should describe concisely in writing the intended strategy and business philosophy for making the vision happen. This is the implementation of the vision:

Customers-who are they? Are they in-house or out-of-house?

Products and Services-what are they? How would you describe them?

Markets-where do you compete? Are there other laboratories like yours that you're going to compete in or with?

Technology - what are the basic technologies that you're trying to promote and sell?

Concern for Survival, Growth and Profitability - this is extremely important, especially in a highly dynamic environment where you're dealing with technology that is constantly moving and constantly developing, and you need to be in front of it. Otherwise, you'll be good for about a week and then after that you'll be left behind.

The Philosophy - what are the beliefs, values, aspirations and philosophical priorities of your laboratory?

Self concept - what are your major strengths and competitive/technological advantages?

Public Image-do you have the desire to be recognized in the public environment?

Employees-what is your concern for employees? These are highly trained and highly skilled individuals who come to work in your laboratories almost exclusively. Look to the care and feeding of these extraordinary people. They need that-trust me.

4) Goals: Again, these are some of the things that you need to put forth.

- Deal with vital issues (including strategic planning) in a timely manner

- Contribute to productivity

- Goals should be measurable and specific

- They need to be applicable to your Vision Statement and your Mission Statement

- They are ordinarily stated as end results. In other words, when we achieve our goal we will be "here" or we will have accomplished "this." 